\title{
AS POLÍTICAS PÚBLICAS DE SEGURANÇA: Entre a repressão e a prevenção criminal
}

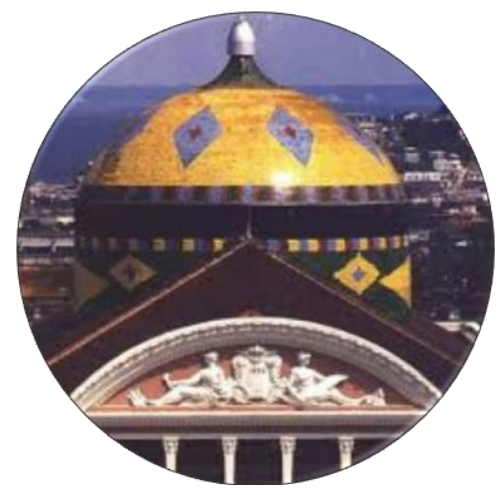

Telma de Verçosa Roessing

Elenise Faria Scherer

\begin{abstract}
Resumo
Este artigo tem como propósito inicial de evidenciar a relação das políticas públicas de segurança com as formas de intervenção estatal, oriundas das transformações que se operam no plano socioeconômico e as respostas estatais aos processos de violência urbana nos anos recentes. Descreve-se, inicialmente, a forte tendência de redução do poder do Estado contemporâneo, bem como a religação das políticas sociais e as políticas penais ou de segurança em diferentes países ocidentais. Para em seguida, destacar a forma como tem sido tratada a questão da segurança pública no Brasil, particularmente a partir de 1995, quando foram criados os planos nacionais de segurança sob a ótica dos direitos humanos; com a reconfiguração do Estado brasileiro e constante crescimento da violência no país, o poder público federal acabou por conduzir as políticas de segurança com prevalência ao modelo repressivo em detrimento de uma tardia garantia de consolidação da cidadania no Brasil. Trata-se de iniciar um debate consubstanciado por análise bibliográfica e documental, cabendo sublinhar que a reflexão é preliminar, com intenções de subsidiar ao processo de investigação, em desenvolvimento, sobre a justiça penal e os usuários de drogas em Manaus.
\end{abstract}

Palavras-chave: Segurança Pública. Intervenção Estatal. Modelo Penal

\begin{abstract}
This article has as its initial purpose to highlight the relationship between public security policies and the forms of state intervention, stemming from socioeconomic transformations and state responses to urban violence processes in recent years. It is firstly described the strong tendency to reduce the power of the contemporary state, as well as the reconnection of social policies and criminal or security policies in different Western countries. To highlight the way in which the issue of public security in Brazil has been dealt with, particularly since 1995 , when national security plans were created from a human rights perspective; with the reconfiguration of the Brazilian state and the constant growth of violence in the country, the federal public authority ended up driving security policies
\end{abstract}


prevalent to the repressive model, to the detriment of a belated guarantee of citizenship consolidation in Brazil. It is a matter of starting a debate based on bibliographical and documentary analysis, and it should be emphasized that the reflection is preliminary, with the intention of subsidizing the research process, in development, on criminal justice and drug users in Manaus.

Keywords: Public security. State intervention. Criminal Model

\section{INTRODUÇÃO}

O tema das políticas públicas na área de segurança gera controvérsias entre doutrinadores e provoca intensos debates entre os acadêmicos e gestores em torno da questão. Nesse âmbito, os debates entre segurança $\mathrm{x}$ insegurança e as respostas estatais dadas, quase sempre são articulados com as novas configurações assumidas pelo Estado contemporâneo com a chamada "crise" do Estado de Bem-Estar, o neoliberalismo e a globalização.

Desde os anos 70, em vários países ocidentais a globalização econômica vem delineando uma forte tendência: a redução do poder do Estado, tornando-o mínimo para as políticas sociais e máximo para as políticas públicas de segurança, gerando o que Wacquant (2001) tem afirmado: um Estado Penal em detrimento de um Estado Social. Nas observações desse autor os processos de desregulamentação econômica se fizeram acompanhar de uma hiperregulação penal, especialmente nos EUA. O desinvestimento social implicou no superinvestimento carcerário. Fenômeno que aparece em muitos países, inclusive no Brasil.

Dentro dessa abordagem, esboçam-se as políticas públicas de segurança formuladas no Brasil desde o ano de 1995 até hoje, que, não se pode desconhecer, foram carregadas de boas intenções, mas, em face da violência brasileira, redundaram na prevalência de políticas imbuídas de maior rigor punitivo, as quais privilegiam o uso do direito penal em detrimento de outras formas de intervenção social. E, mais ainda, passaram ao largo das causas que propiciam a violência. 
Cabe destacar, entretanto, a tentativa do Estado brasileiro de associar segurança pública, derivada do poder coercitivo estatal, com cidadania plena, como pode ser observado nos Planos Nacionais de Direitos Humanos e, principalmente, com a implantação do Programa Nacional de Segurança Pública com Cidadania - PRONASCI, em 2007, o qual ainda se apresenta de forma tímida no estado do Amazonas.

$\mathrm{Na}$ ótica desses Programas governamentais, constata-se que, para manter o mínimo de garantias sociais, o principal desafio do país é o de insistir na construção de política de segurança efetiva e alternativa ao modelo essencialmente repressivo, prevenindo às práticas violentas e delituosas, por meio de políticas públicas específicas e eficazes de inclusão social, preferencialmente no sentido da inclusão produtiva, e que sejam contínuas, duradouras e venham acompanhadas de políticas redistributivas, que combatam as desigualdades sociais e o aumento da violência.

Ao abordar, sinteticamente, as mudanças ocorridas na forma de intervenção estatal decorrentes de transformações ocorridas no plano econômico e social, as quais influenciam a formulação de políticas públicas voltadas para área de segurança, pretende-se, com o presente artigo, apreender essas transições que provocaram uma reconfiguração do Estado brasileiro nas últimas décadas. Criar um solo sócio-histórico que permita compreender os Programas de governo para área da segurança pública, para mais adiante criar um aporte teórico que possibilite entender a predominância do Estado Penal, com suas medidas repressivas em detrimento de políticas preventivas e estruturais de cunho social nos tempos presentes.

\section{As políticas públicas e a intervenção estatal}

As políticas públicas podem ser entendidas como estratégias de intervenção e regulação do Estado no que diz respeito à questão social. 
Criadas como resposta do Estado às demandas que emergem da sociedade e de seu próprio interior, são expressão de compromisso público de atuação numa determinada área em longo prazo (CUNHA e CUNHA, 2008).

Alguns autores, entretanto, se referem a políticas de governo ou governamentais em oposição à denominação políticas públicas. Há de se destacar que a dimensão política da palavra pública é decorrente de um conjunto de decisões e ações que resultam simultaneamente da ingerência do Estado e da sociedade (PEREIRA, 2008). Se é assim, supõe emprestarlhes um caráter mais estável e inflexível, as quais obrigariam os governos de um Estado a implementá-las, independentemente do momento histórico e sociopolítico.

Na ótica de Heidemann (2009), a perspectiva de política pública, vista de forma mais ampla, vai além das políticas governamentais, pois o governo, com sua estrutura administrativa, não é a única instituição a servir à comunidade, ou seja, a promover políticas públicas, embora historicamente o Estado seja provedor clássico das provisões sociais destinadas aos segmentos mais pauperizados de determinadas sociedades.

As políticas públicas são classificadas, de acordo com Meny e Thoenig (1995), de reguladoras, constitutivas, distributivas e redistributivas e têm, ainda, um sentido compensatório. Tais tipologias envolvem, sempre a ação do Estado e da sociedade, no combate às desigualdades decorrentes do acesso diferenciado a recursos econômicos ou de processos culturais que não consideram especificidades de segmentos sociais denominados como minoritários.

Como bem ressalta Souza (2006), "as políticas públicas repercutem na economia e nas sociedades, daí porque qualquer teoria da política pública deve, também, explicar as inter-relações entre Estado, política e sociedade”. Significa dizer que, nesse sentido, a interferência estatal deve zelar pela adoção de políticas públicas eficazes, principalmente relativas aos direitos 
sociais, pois o desenvolvimento de uma sociedade não é apenas sinônimo de crescimento econômico, mas sim de segurança humana de forma mais abrangente, a qual contempla os processos socioeconômicos, políticojurídicos e, também, a segurança pública.

\section{O monopólio da força e as políticas públicas}

Nos argumentos weberianos, o Estado detém o monopólio da força, ou seja, o conjunto de poderes e de tarefas associados à segurança pública e à ordem jurídica. Como afirmam Ruediger e Riccio (2005), a segurança nos últimos anos é um dos itens mais importantes dentro de uma agenda positiva de políticas públicas, face aos índices crescentes de criminalidade e de violência urbana.

A Constituição de 1988 assegurou os princípios da cidadania e de justiça social, contudo, a timidez na formulação das políticas de segurança pelos governantes brasileiros não permitiu, até o momento, efetivas mudanças que possibilitassem e estendessem a cidadania aos diversos segmentos socialmente desprovidos da sociedade.

As transformações ocorridas nos últimos vinte anos do século XX trouxeram uma nova ordem global, tendo como consequência a precarização das relações de trabalho, a ampliação da vulnerabilidade social, a exclusão social e a degradação ambiental. Essa globalização, de cunho neoliberal, reforça a ética individualista burguesa com base no consumo exacerbado e na mercantilização das dimensões da vida moderna (DORNELES, 2008).

Ao seguirem a lógica do mercado, as relações sociais caracterizam-se pelo individualismo, pela competição, pelo imediatismo, pelo egoísmo, pela ausência de solidariedade no convívio, favorecem percepção negativa de riscos, gerando fortes sentimentos de incômodo e de medo, que dão lugar a difusos anseios de segurança (KARAM, 2004). Tendência essa reforçada 
por Santoro (2002), o qual afirma que, para conservar-se e reproduzir-se, a nova ordem mundial precisa de Estados reduzidos aos seus poderes de repressão, fracos e diminutos para a reprodução da força de trabalho, mas fortes para o capital.

Em perspectivas analíticas semelhantes Werneck Vianna (2008), ao se reportar aos países ocidentais, refere-se que "o lugar vaz̧io do Estado do BemEstar será ocupado pelas instituicõoes de Justiça." Vê-se na atualidade que os indivíduos desprotegidos na ordem neoliberal acorrem, em geral, à judicialização para ter acesso às suas demandas, por saúde, educação, sobretudo em um Estado que negligencia suas obrigações sociais, privilegia o viés penal repressivo nas suas formulações e provoca expansão desenfreada de outras formas de "supervisionar a vida dos pobres" (WACQUANT, 2001), por conseguinte, o encolhimento das garantias sociais, de distribuição de renda que reduza as desigualdades sociais.

Esse movimento surge em decorrência do enfraquecimento do Estado Social, como pretenso garantidor dos direitos sociais, que dá lugar, em diversos países do mundo ocidental a um Estado de cunho penalista, provedor, em última instância da segurança, nem que seja de forma meramente simbólica (WACQUANT, 2007).

\section{Do Estado Social ao Estado Penal}

As demandas por segurança situadas nas áreas de confluência da economia com o direito penal são vistas por alguns doutrinadores, intelectuais e gestores como a passagem do Estado Social para o Estado Penal. Razão para se perceber que o debate sobre a segurança pública fica tendencialmente reduzido à política penal. Em decorrência, a sociedade que exigia um Estado com políticas sociais, passou-se a uma sociedade que privilegia o discurso penal. 
A esse respeito, Wacquant (2007) afirma que, nas sociedades chamadas "pós-industriais", surge um novo sistema de marginalidade social. Nessas sociedades, a pobreza deixou de ser residual, cíclica e transitória. Ao contrário, está inscrita na vida social societária contemporânea. E desde os anos 80 do século XX, assiste-se à hipertrofia do Estado Penal, em detrimento de um Estado Social, ${ }^{1}$ a exemplo do que ocorre na política de segurança pública dos Estados Unidos, onde, segundo o referido autor, houve a retração da rede de seguridade social, com cortes orçamentários nas políticas de assistência, saúde, educação e habitação, e o deslocamento de recursos para a segurança pública, revelando o viés repressivo e punitivo da política governamental naquele país.

Para conter as tensões geradas pelo desemprego em massa, pela imposição do trabalho precário e pela retração da proteção social, o Estado lança mão de estratégias de disciplinamento de segmentos da classe operária, por meio do aparato policial e jurídico num contexto da crise do capital, a qual afeta todas as instâncias da vida social. A crise contemporânea do capital, segundo Antunes (2005), se expressa de forma aguda e destrói a força humana que trabalha, destroça direitos sociais, brutaliza enormes contingentes de homens e mulheres que lutam pela subsistência cotidiana e transforma em predatória a relação produção/natureza.

Santoro (2002) assinala que existe uma tendência acentuada para uma gestão judiciária da pobreza na medida em que a política econômica e social dos governos mais recentes se inspira nas teorias neoliberais da "privatização" das relações sociais, num contexto em que as garantias do Estado Social são sempre mais débeis enquanto o Estado policial e penal é

1 O Estado Social ou Estado de Bem-Estar Social ou Welfare State se refere "ao modelo estatal de intervenção na economia de mercado que, contrário ao modelo liberal que o antecedeu, fortaleceu e expandiu o setor público e implantou e geriu sistemas de proteção social" (PEREIRA, 2009). 
reforçado. E complementa o autor acima: "o crescimento dos recursos destinados à manutenção da ordem pública preenche, em primeiro lugar no plano simbólico, o vazio de legitimidade deixado pela renúncia ao governo da economia e à rede de seguridade social", neste último caso, no sentido de garantia dos direitos sociais.

A repressão penal, por esse viés, passa a ser a prática sociopolítica vigente por meio de políticas de segurança pública, dentro do contexto da modernidade recente que, com a sua lógica inclusiva, disciplinar e integradora no mercado de consumo, é altamente excludente. Um modelo que, ao excluir, produz e amplia o conflito social, produz e amplia a incerteza, o medo, a miséria, para aqueles que não têm lugar no mundo (CASTEL, 1995).

$\mathrm{Na}$ visão de Wacquant (2001), o Estado penal, para responder aos problemas agravados pela desregulamentação da economia e dos elevados índices de pauperização, intensifica a ação do aparelho judicial e policial, privilegiando o recurso do sistema penitenciário como forma de conter o aumento expressivo da pobreza e das desigualdades sociais. Pode-se deduzir a ligação estrita entre a difusão de políticas de segurança e as políticas neoliberais, hoje apresentadas como necessidade imposta pela globalização, cujo eixo é a onipotência do mercado.

Os Estados enfraquecidos de suas capacidades de intervenção social, expandiram as várias formas repressivas com objetivo de coesão social. A criminalização acaba focada nos segmentos socialmente vulneráveis, os quais não têm espaço no mercado formal, aqueles que Dorneles (2008) chamou de "consumidores falhos".

$\mathrm{Na}$ América Latina, a maioria dos países enfrenta a questão da segurança pública com base no paradigma da contenção, ilustrado, segundo Rolim (2008), pelo discurso da "lei e ordem", ou melhor, pelo foco maior na repressão, na tentativa de evitar o descontrole social. As políticas de segurança pública que ora se apresentam, deslocam a atenção dos 
indivíduos e dos motivos que os levaram a cometer o crime, para as categorias e os grupos sociais considerados de risco, ou seja, os que se encontram em condições de vulnerabilidade social e não conseguem acompanhar o ritmo imposto pela competitividade do mercado. E dentro dessa ótica repressiva estão o aumento de penas e o recrudescimento do sistema carcerário.

\section{As políticas públicas de segurança no cenário brasileiro}

Há de se destacar, de início, que no Brasil não se experimentou um Estado Social. Aqui, costuma-se afirmar, vivencia-se um estado de mal estar, em vista das crescentes desigualdades sociais e da precariedade das políticas de seguridade social. As atuais estatísticas oficiais, registram, inclusive, aumento dos índices de pobreza e de miséria. ${ }^{2}$

A revista semanal Carta Capital (205/2014), baseando-se nos documentos oficiais, tais como Mapas da Violência entre outros, ressalta que a prática de atos criminosos têm sido claramente relacionados àqueles que vivem nas zonas do não-direito (WACQUANT, 2007). Esses indivíduos sociais considerados à margem da ordem capitalista, por sua vez, constroem formas de resistência individuais e coletivas para sobreviver ao poder dos donos do poder. Neste cenário, o Estado lança mão dos seus aparatos repressivos no sentido de conter o retorno das chamadas "classes perigosas" que, na lógica da criminalização são constituídas por jovens pobres e negros, a população de rua, assim como, os movimentos sociais urbanos e rurais, os quais são os alvos preferenciais da polícia.

2Dados do Instituto de Pesquisa Econômica Aplicada (Ipea) mostram que o total de pessoas que vivem na extrema pobreza passou de 10.081.225, em 2012, para 10.452.383 em 2013. A proporção de extremamente pobres subiu de 5,29\% para $5,50 \%$ (EXAME, 2014). 
Evidencia-se que nos anos oitenta o Brasil, assim como os países vizinhos do continente, enfrentou uma das suas piores crises financeiras, contribuindo para isso o aumento da dívida externa, a inflação, a crise fiscal, a crise do petróleo e problemas com o financiamento externo, levando o governo brasileiro a implantar alguns planos econômicos na tentativa de conter a inflação e a desvalorização do câmbio. Isto provocou uma onda de desemprego e de reformas que tornassem o Brasil um país mais competitivo. No entanto, "o Poder Público foi incapaz de implementar políticas públicas coerentes, com superposição e consecução apenas parcial de diversos planos ao mesmo tempo" (BERCOVICI, 2005).

Nesse contexto de crise e de mudanças internacionais sob a ótica de menos intervenção e mais mercado, os deputados constituintes, em 1988, conseguiram consagrar, do ponto de vista da lei, uma Carta Constitucional com característica do que se poderia dizer de um liberalismo social-democrata que, ao conservar os ditames da ordem do capital asseguraria os direitos de cidadania, em uma conjuntura na qual o mundo capitalista ocidental já vivia a era neoliberal, em pleno vigor nos países europeus, a exemplo do Reino Unido, nos EUA e no Chile de Pinochet, na América Latina.

Mesmo a despeito desse panorama, os constituintes optaram por um Estado provedor. Não se restringiram a atribuir ao Estado a tarefa de garantir direitos básicos ao cidadão e de pagamento da "dívida social" acumulada ao longo da história. As vozes contrárias no âmbito do debate constituinte que discordavam do intervencionismo estatal e coerente com a onda neoliberal alertavam à sociedade brasileira que a Constituição estava a contramão da história, ou seja, anacrônica em tempos de globalização. Nesse embate, resultou a dificuldade de garantir aos cidadãos, por meio de legislação complementar, direitos básicos, como saúde, educação e segurança. 
A partir de 1995, ano processo de contrarreformas (SCHERER, 2001) reconfiguram-se as minimas sociais direcionadas aos segmentos focalizados da população brasileira, como indicava o receituário neoliberal. As políticas de seguridade social, previdência social, saúde, assistência e a educação sofrem retrações significativas, sem levar em conta que uma sociedade só pode prosperar no exercício de suas liberdades e de seus direitos políticos, se tiver uma base mínima que a qualifique para isso.

Nesse tempo histórico, fica evidenciado que a participação direta do Estado na atividade econômica restou vinculada aos imperativos da segurança nacional e ao relevante ao interesse econômico ${ }^{3}$. O certo é que o modelo constitucional redesenhado para o Estado brasileiro, a nosso ver, não se apresenta como liberal minimalista e nem como Estado provedor como pretendiam os deputados constituintes, mas como um Estado regulador. Quer para si as atividades essenciais, reconhecendo a impossibilidade de executar outras, transferindo-as, mas supervisionando-as por intermédio de atividade gerencial e reguladora.

Essas reformas aconteceram no período correspondente à primeira gestão do presidente Fernando Henrique Cardoso (1995-1998), na qual as políticas desenhadas para a área da segurança pública insistiam em privilegiar lei e ordem, como tradicionalmente ocorre em nossa história, aspecto bem representado no lema positivista de nossa bandeira nacional.

3A Constituição é carregada de ambiguidades. No artigo 173, dispõe: "Ressalvados os casos previstos nesta Constituição, a exploração direta de atividade econômica pelo Estado só será permitida quando necessária aos imperativos da segurança nacional ou a relevante interesse coletivo, conforme definidos em lei." No entanto, um Estado que não se afasta completamente da economia fiscalizando, incentivando e planejando-a, por ser seu agente normativo e regulador, conforme estabelece o artigo 174 do mesmo diploma legal: "Como agente normativo e regulador da atividade econômica, o Estado exercerá, na forma da lei, as funções de fiscalização, incentivo e planejamento, sendo este determinante para o setor público e indicativo para o setor privado." 
De acordo com Adorno (1999), o governo chegou a afirmar na época que não se tratava de "escolher entre o Estado-polícia e o Estado de bem-estar social", pois, entendia-se que a capacidade do Estado prover bem-estar dependia, em certa medida, do seu poder coercitivo.

Houve, entretanto, nesse período a implantação do I Plano Nacional de Direitos Humanos, coordenado pelo sociólogo Paulo Sérgio Pinheiro, do Núcleo de Violência da USP, o qual contemplava parceria com a sociedade civil e a segurança, elegendo a questão dos direitos humanos como essencial à consolidação da democracia no Brasil. Sem dúvida, esse plano conseguiu colocar os direitos humanos na agenda política brasileira, mas não conseguiu convencer o cidadão comum de que a questão da segurança pública não pode estar desvinculada da promoção e proteção desses direitos.

Adorno (1999) pontua que embora o referido programa tenha trazido como fundamento a "concepção de indivisibilidade dos direitos bumanos", não abordou a questão dos direitos econômicos e sociais, priorizando no campo da segurança pública as violações de direitos humanos cometidas por agentes policiais como requisito de pacificação social.

No segundo governo de Fernando Henrique Cardoso (1999-2002) destacam-se o II Plano Nacional de Direitos Humanos ${ }^{4}$ e o I Plano Nacional de Segurança Pública, os quais buscavam cooperação entre governo federal e governos estaduais nas tratativas das questões relacionadas à segurança pública e sinalizavam para ações de cunho preventivo, dentre essas, a tentativa de reduzir riscos de envolvimentos de adolescentes e jovens adultos no consumo e tráfico de drogas, promover maior envolvimento da sociedade civil e de comunidades na redução do

4 Planos Nacionais de Direitos Humanos I e II: PNH I - Decreto $n^{0} 1.904$, de 13/05/1996; PNH II - Decreto $n^{\circ} 4.229$, de 13/05/2002. 
crime e da violência urbana, além da erradicação do trabalho infantil (ADORNO, 2003).

Tanto no primeiro como no segundo governo de Fernando Henrique Cardoso, os gestores estatais tiveram dificuldades de implantar as ações de segurança pública. Sabe-se que não é tarefa fácil associar a questão da segurança pública com direitos humanos, sobretudo em uma sociedade que aplaude e defende os direitos humanos, mas também é composta de uma elite com ranços conservadores e antidemocrática como a nossa, que teima em não querer compreender que os direitos humanos não foram consolidados somente para proteger "bandidos", como muitos afirmam. E insistem nas formulações do direito penal como primeira forma de punição por parte dos governos.

No prefácio da edição brasileira de As Prisões da Miséria, Wacquant (2001) reforça os argumentos cotidianos a despeito do nosso país ser uma potência econômica, cujo enriquecimento acumulado ao longo de sua história, continua caracterizado pelas desigualdades sociais, pela pobreza e pela miséria que, ao se combinarem, alimentam o crescimento inexorável da violência criminal, transformada em principal flagelo das grandes e médias cidades. E acrescenta, "ao invés do tratamento social da miséria e de seus correlatos - ancorado na visão de longo prazo guiado pelos valores de justiça social - historicamente têm dado ênfase ao tratamento penal".

$\mathrm{Na}$ verdade, o direito penal só deveria ser acionado quando outras formas de intervenção já tivessem sido tentadas. Garantir segurança pública não é só reprimir, mas também assegurar que os direitos de cidadania, como prescreve a Carta de 1988, sejam respeitados e implementados, por meio de ações em outras esferas de governo, como saúde, educação, assistência social, planejamento urbano etc.

Como bem sustenta Zaluar (1997), o problema da segurança pública não será resolvido apenas com o foco no sistema de justiça, que pune o criminoso menor, menos importante no circuito dos envolvidos e, 
geralmente, menos responsável pelo início do fluxo das atividades criminosas. Além disso, o crime é uma questão social que não pode ser deixada apenas nas mãos de policiais, advogados ou juízes (BEATO FILHO, 1999).

As políticas de segurança pública dos governos FHC, apesar de não terem deixado resultados práticos significativos, criaram raízes para a implementação das políticas de direitos humanos e de segurança pública nos governos de Luiz Inácio Lula da Silva, que encontraram algo em que se apoiar, dando sequência, inclusive, aos Planos Nacionais de Direitos Humanos, com o lançamento, em 2009, do Plano Nacional de Direitos Humanos, em sua terceira edição. ${ }^{5}$

Ressalta-se, portanto, a tentativa do governo brasileiro de associar segurança pública com cidadania, como está constitucionalmente prescrito. Razão para esses princípios fundamentais estarem incorporados no Programa Nacional de Segurança Pública com Cidadania - PRONASCI, lançado em 2007 (Lei n.o 11.530, de 24/10/2007) e desenvolvido no âmbito do Ministério da Justiça, destinando-se à prevenção, ao controle e a repressão da criminalidade, atuando em suas raízes socioculturais, além de articular ações de segurança com as políticas sociais por meio da integração e descentralização entre União, estados e municípios.

O diferencial do projeto está na articulação de políticas de segurança com ações sociais, atacando as causas da violência e não apenas as suas consequências, mas procurando articulá-las com questões econômicas. O Programa ressignifica o conceito de segurança pública.

Para que haja efetiva segurança pública, segurança jurídica, segurança política e econômica, num projeto democrático, é preciso que se promova uma coesão social de novo tipo. Ou seja, o sentimento de "pertencimento" à sociedade e de integração dos

5PNH III - Decreto n ${ }^{\circ} 7.037$, de 21/12/2009 
cidadãos no projeto nacional deve se dar por meio de marcos jurídicos e políticos que surjam e pertençam, também, aos "de baixo". É preciso que esses se sintam vinculados moral e politicamente ao Estado, que, além de garantir as suas liberdades formais, deve ser permeável às suas demandas essenciais e assim propor uma melhora contínua em sua vida cotidiana, no trabalho, na família e no espaço público. Enfim, para que o Estado seja uma instituição efetivamente significativa na construção da dignidade de todos e, por isso, seja percebido e respeitado. (BRASIL/MJ, 2009a).

Foi proposto, assim, um novo paradigma de segurança pública pautado em duas grandes inovações:

Fomento de uma agenda federativa compartilhada, com envolvimento de todos os entes, acrescentando, ao papel basilar dos estados, O Governo federal, com indução de políticas e financiamento, e os municípios com papel ativo nas ações de prevenção. (BRASIL/MJ, 2009b).

Para o Ministério da Justiça "esse novo paradigma se traduz na promoção de um projeto de inclusão e fortalecimento da coesão social, por meio do empoderamento das relações entre operadores de segurança e sociedade civil e do acesso a um Estado qualificado” (BRASIL/MJ, 2009b).

O público-alvo do projeto são prioritariamente os jovens de 15 a 24 anos, egressos do sistema prisional, moradores de rua, em descontrole familiar e em conflito com a lei, os presos e os adolescentes infratores. Por seu caráter descentralizado caberiam aos estados e aos municípios articularem-se junto ao poder judiciário, apresentando projetos de combate a violência e a afirmação dos direitos humanos, com recursos provenientes do PRONASCI para atuar em relação a qualquer desses segmentos acima descritos.

O Programa visa ao desenvolvimento de ações estruturais e programas locais, tais como: a modernização das polícias e o sistema prisional, valorizar os profissionais do setor, combater a corrupção policial 
e o crime organizado. Já os programas locais têm o objetivo de retirar jovens da rota do crime e inseri-los nos programas sociais mantidos pelos governos.

Entre os programas locais que se destacam está o Território de Paz, que consiste na implantação de pacote de ações preventivas integradas e simultâneas, que fazem com que o Estado passe a retomar o controle nas regiões conflagradas, oferecendo acesso aos serviços públicos e melhorando a qualidade de vida da população. Os territórios devem ser implantados, prioritariamente, nas regiões metropolitanas que registram índices de violência mais elevados. O primeiro passo para a instalação do Território de Paz é a chegada da Polícia Comunitária que conta com profissionais mais preparados para atender a comunidade, os quais fazem ronda sempre na mesma região e dialogam com os moradores, conhecendo suas rotinas e necessidades.

O projeto Mulheres da Paz é ação prevista no Território da Paz, pelo qual se dá bolsas de estudos para as mulheres que queiram participar do programa. Elas são capacitadas em temas como ética, direitos humanos e cidadania e tem a incumbência de identificar os jovens com os quais o PRONASCI atua.

Destaque-se, a exemplo, o projeto dos Promotores Legais Juvenis. Por meio desta ação, os jovens bolsistas agem como multiplicadores da filosofia passada a eles pelas Mulheres da Paz. O objetivo é atingir outros rapazes e moças, além das famílias, e contribuir para o resgate da cidadania nas comunidades.

Isso tudo deve acontecer com o auxílio dos Conselhos Comunitários Municipais, Gabinetes de Gestão Integrada Municipal (GGIM) e as equipes multidisciplinares, tais como os assistentes sociais, os psicólogos, os educadores, os pedagogos, entre outros.

A qualificação das polícias em práticas de segurança-cidadã é, também, atribuição do PRONASCI. Dentre essas práticas se insere o 
policiamento com armas não-letais. $\mathrm{O}$ investimento em técnicas de investigação, como laboratórios de DNA Forense, e em cursos de especialização também faz parte do pacote.

Destacam-se, ainda, os programas de transferências de renda por meio do projeto bolsa-formação aos policiais militares que ganham abaixo de $\mathrm{R} \$ 1.700,00$ por mês. A bolsa destina-se a melhorar a sofrível qualificação profissional da maioria dos policiais brasileiros, os quais têm que fazer curso de reciclagem para receber o benefício, e ao mesmo tempo promover condições mais dignas de trabalho.

O ex-ministro da Justiça Luiz Paulo Barreto, no discurso de abertura do $12 .^{\circ}$ Congresso das Nações Unidas sobre Prevenção ao Crime e Justiça Criminal, ocorrido na Bahia no ano de 2010, afirmou:

A democracia está assentada no dever do Estado de garantir a todos os cidadãos os direitos básicos, entre os quais o direito à segurança pública. Somente através da garantia da segurança, da paz e dos demais direitos inerentes à cidadania, é possível o desenvolvimento econômico e social de uma nação. Por essa razão as políticas de segurança não podem estar dissociadas de políticas que assegurem educação, saúde e bem-estar, oferecendo oportunidades de desenvolvimento aos segmentos e grupos mais vulneráveis. É nessa perspectiva que se insere o PRONASCI, já mencionado, que corresponde a um novo paradigma da política de segurança pública no Brasil, na medida em que articula políticas de segurança com ações sociais, dando ênfase à prevenção e buscando atingir as causas que levam à violência, muitas vezes ligadas a vulnerabilidades sociais. O programa inova, ademais, pelas ações multidisciplinares, que têm como eixo o respeito aos direitos humanos e a participação da sociedade civil. (12. ${ }^{\circ}$ CONGRESSO DAS NAÇÕES UNIDAS SOBRE PREVENÇÃO AO CRIME E JUSTIÇA CRIMINAL, 2010).

O PRONASCI foi criado, portanto, para articular políticas de segurança com ações sociais, priorizando a prevenção e buscando atingir as causas que levam à violência, sem abrir mão das estratégias repressivas 
necessárias e se apresentou como iniciativa inédita no combate à criminalidade no país.

Nova relação federativa se instaurou no âmbito da segurança pública, a qual, mesmo sendo prerrogativa constitucional do Estado, passou a ser tratada também pelos Municípios, que passaram a atuar com a União na questão, com importante papel de enfrentar a criminalidade com ações preventivas, contando com apoio do Ministério da Justiça no financiamento de projetos (BRASIL, 2014). O referido Programa surgiu para tentar mudar o paradigma da segurança pública no país, com a introdução de uma cultura de paz e cidadania na ação policial, visando a diminuir os índices de violência e aumentar sensação de segurança na população.

Em 2009, pesquisa da Fundação Getúlio Vargas - FGV, baseada em consulta feita à população e aos policiais, indicou que o PRONASCI não havia trazido, ainda, os efeitos esperados, na medida em que não apresentava indicadores de redução de violência em dois anos de implantação.

O Ministro da Justiça Tarso Genro argumentava na época que "as estatísticas são demoradas", afirmando que as informações mais imediatas poderiam ser fornecidas no futuro pelos gabinetes integrados de segurança pública. 'Não haverá mudança espetacular e rápida. Índices significativos aparecerão em quatro a cinco anos, dependendo da região", completou (BRASIL, 2014).

O Instituto de Pesquisa Econômica Aplicada - IPEA analisou o desempenho do PRONASCI, indicando a positividade do programa porque logrou reunir em projeto unificado um conjunto de ações e também porque incentiva a participação dos municípios na elaboração das políticas públicas de segurança. Porém, a sua gestão tende a ser dificultada pelo fato de combinar ações muito díspares, desde o enfrentamento da violência até a instalação de pontos de cultura, passando pela recuperação urbana das 
áreas vulneráveis, os programas de renda mínima e a capacitação dos policiais (BRASIL, 2014). Provavelmente tais dificuldades ocorrem, também, devido as ações do programa serem interministeriais, sujeitas aos entraves da burocracia reinante no serviço público brasileiro.

Em 2011, segundo fonte do Ministério da Justiça, todos os princípios e diretrizes introduzidos pelo PRONASCI na área da segurança pública passaram a ser orientadores de toda a política nacional conduzida pelo governo federal. Isso significa que o conceito do PRONASCI deixou de ser restrito a um dos programas da União e passou a direcionar todas as ações realizadas nacionalmente (BRASIL, 2014).

As notícias postadas na seção destinada ao PRONASCI no sítio do Ministério da Justiça não indicam grandes investimentos recentes nas políticas sociais dentro do viés da segurança pública, podendo-se inferir que o governo de Dilma Rousseff parece ter se afastado da essência do Programa (BRASIL, 2014). As informações veiculadas pela mídia são as de que as prioridades mudaram, pois o governo federal tem demonstrado que os interesses maiores passaram a ser o controle das fronteiras, o combate ao crack, no sentido de "guerra" contra as drogas, e a modernização do sistema penitenciário.

Fica demonstrado, assim, que existe um movimento pendular nas políticas públicas de segurança no Brasil, no qual o foco na repressão tende a se sobrepor ao da prevenção e ao do resgate das relações sociais. Por isso mesmo, Soares (2006) assinala que o quadro da violência criminal se constitui em tragédia em nosso país, haja vista que afeta muito mais a juventude pobre, negra e do sexo masculino.

O Mapa da Violência (2013a), intitulado "Mortes Matadas por Armas de Fogo", e o Mapa da Violência (2014), sobre o "Homicídio e Juventude no Brasil", ambos organizados por Julio Jacobo Waiselfisz, evidenciam índices alarmantes de homicídios cujas vítimas são jovens entre 15 a 29 anos, com aumento de mortes de jovens do sexo masculino negros 
ou pardos. No que concerne a mortes ocasionadas por armas de fogo, a cifra é, ainda mais, assustadora, pois, das 799.226 pessoas vítimas de arma de fogo, entre 1980 até 2010, 67\% eram jovens na faixa etária mencionada (WAISELFISZ, 2013a).

O autor citado analisa, ainda, os dados da violência letal que atinge os jovens brasileiros (WAISELFISZ, 2014) e considera como mortalidade violenta a resultante da somatória de homicídios, suicídios e acidentes de transportes. Nesse conjunto, conclui que, a partir dos 19 anos de idade e até os 26, as taxas de mortalidade violenta ultrapassam os 100 óbitos por 100 mil jovens.

No que concerne à Região Norte, as taxas de homicídios na população total cresceram na década 2001-2011, sendo o aumento, nesse período, de 75\%. O estado do Amazonas, dentre outros, teve aumento de suas taxas de forma acentuada e descontrolada, afetando as condições de seguridade cidadã. (WAISELFISZ, 2013b).

Relativamente aos níveis de violência que ceifam a juventude das capitais, as taxas apresentadas atingem marcas inaceitáveis no Brasil. E Manaus se encontra entre as capitais que os índices ultrapassam 100 homicídios por 100 mil jovens. (WAISELFISZ, 2013b).

Quando avalia a evolução decenal da violência nos Estados, Waiselfisz, (2013b), sugere que os elevados índices de crescimento das taxas de criminalidade violentas estaduais e nas capitais, podem estar associadas à incapacidade e/ou ineficiência dos aparelhos de segurança locais de enfrentar o novo quadro de violência, citando como exemplo os estados do Amazonas, Bahia, Rio Grande do Norte e Goiás.

Para que esse quadro não se agrave, se faz necessário a implementação de políticas inteligentes, pluridimensionais, intersetoriais e sensíveis às especificidades locais que possam romper os ciclos de desigualdade entre as pessoas, como a pobreza, a qualidade de vida 
degradada, as deficiências de escolaridade e a precariedade no acesso aos direitos fundamentais.

Quanto à implantação do PRONASCI, tem-se notícias que o Amazonas caminha a passos lentos, concentrando-se sobretudo na cidade de Manaus, esquecendo as cidades interioranas. Sob a ótica da polícia comunitária foi criado o programa Ronda no Bairro com objetivo de criar um ambiente de segurança, aproximar-se e estreitar um diálogo com as famílias residentes nos bairros onde os índices de violências são enormes. Não de descurou também nas zonas residenciais nobres como nas zonas centrais da cidade, mas só expandiu-se para as cidades interioranas mais próximas.

O Relatório Anual da Secretaria de Segurança Pública do Estado do Amazonas, publicado em 2013, apresenta diagnóstico da criminalidade com base em dados produzidos no estado em 2012 e mostra que a violência urbana em Manaus, comparada ao ano anterior, teve queda acentuada naquele ano, se as sete zonas administrativas da cidade (CentroOeste, Centro-Sul, Leste, Norte, Oeste, Sul e Rural) forem consideradas como um todo. Atribuiu-se tal declínio às mudanças operacionalizadas no Sistema de Segurança Pública, principalmente na capital.

Por outro lado, se tais zonas administrativas forem consideradas separadamente, fica demonstrado que, no ano de 2012, nas Zonas Norte e Leste, consideradas mais pobres e populosas, os índices de criminalidade, relativos aos crimes de homicídio, lesão corporal e estupro aumentaram, podendo-se inferir que as ações promovidas pelo aparato de Segurança Pública em Manaus ainda não fizeram surgir grandes efeitos nos bairros mais pobres. Outros dados evidenciam, ainda, que, de maneira geral, houve aumento das taxas de criminalidade na capital no que diz respeito aos crimes de tráfico de drogas e porte de drogas para consumo próprio.

O referido Relatório reconhece, ainda, a necessidade urgente de melhorar a cobertura dos dados produzidos no estado do Amazonas, 
principalmente no que se refere à coleta de dados nas cidades do interior. E, em conclusão, afirma que o tema da criminalidade é complexo e exige ações coordenadas, tanto no Sistema de Segurança Pública quando no Sistema de Justiça. Esqueceu, todavia, de mencionar que há necessidade, talvez de forma prioritária, de se promover ações de caráter preventivo de cunho social, visando a evitar, principalmente, a reincidência criminal.

\section{CONSIDERAÇÕES FINAIS}

A questão da segurança pública tem sido enfrentada pela maioria dos países com o recurso tradicional, que tem como base os paradigmas da repressão. Além do controle do Estado sobre seus cidadãos, denota-se que o problema da segurança pública está ligado a condicionantes de ordem político-social e econômica.

Por outro lado, não se pode esquecer que a criminalização dos pobres não se constitui em estratégia recente, basta lembrar o sistema das Poor Law do século XVIII e a sua reforma na década de 30 do século XIX, entre outras leis que expressam nitidamente as formas de controle dos pobres (PEREIRA, 2009)

As sucessivas mudanças nos modelos estatais, de um Estado Liberal para um Estado de Bem-Estar e posteriormente o surgimento de um Estado híbrido (FEITOSA, 2007) ${ }^{6}$ com matizes social e liberal, propiciaram uma reorganização social, por meio da aplicação de políticas de contenção de gastos e mecanismos repressivos. Essas políticas, geralmente, se voltam para segmentos da sociedade que não conseguem acompanhar o

6"É aquele que procura conviver com a iniciativa privada, estimulando-a e subsidiando-a, sem, entretanto, descurar-se de impor de certas limitações sobre os poderes econômicos, da regulação das atividades econômicas e sociais e da tutela dos menos favorecidos." (FEITOSA, 2007). 
ritmo imposto pelo mercado. Fica evidenciado que existe uma relação entre os processos econômicos e o projeto estatal de políticas de segurança.

Percebe-se que o crescimento dos recursos destinados à segurança pública de cunho meramente repressor decorre das dificuldades dos poderes estatais em face das manifestações da questão social. A política de repressão penal destina-se a enfrentar a desintegração social provocada pela retirada do Estado provedor, em países como os EUA, como evidencia Wacquant (2007).

No caso brasileiro, a Constituição de 1988, institucionalizou, pelo menos formalmente, os direitos sociais. No entanto, paradoxalmente, ela foi elaborada no âmbito de um movimento mundial de cunho neoliberal, em que o poder do Estado foi reconfigurado, dificultando o atendimento das demandas sociais.

Os governantes recentes, diante do cenário de violência urbana envolvendo sobretudo os jovens e à luz dos direitos fundamentais prescritos na Carta de 1988, tentaram criar as políticas públicas de segurança no país intercruzando os processos econômicos com os direitos humanos. Razão para a implementação do Programa Nacional de Segurança Pública com Cidadania - PRONASCI, com objetivo de articular a questão da segurança pública com ações sociais de combate à pobreza e as desigualdades sociais.

Observa-se, contudo que o discurso da lei e da ordem persiste nas ações de segurança, face ao aumento assustador da criminalidade em nosso país, tais como evidenciam as pesquisas. O direito penal reemerge como forma simbólica na tentativa de diminuir a sensação de insegurança da sociedade. As políticas sociais desenvolvidas institucionalizam a pobreza, mas, efetivamente, não se pode dizer que contribuem para retroceder os índices de violência. Ademais, no âmbito do PRONASCI a multiplicidade de políticas de cunho social acabaram ficando em segundo plano. 
No Estado do Amazonas o PRONASCI caminha a passos lentos, embora as instituições educacionais tenham dedicado a qualificar os recursos humanos, criando cursos de graduação e pós-graduação lato sensu para os quadros policiais e, com apoio do Ministério da Justiça, oferecendo cursos de extensão em Direitos Humanos, não só na capital como em municípios interioranos mais próximos. A experiência concreta, a exemplo do Projeto Ronda nos Bairros, entretanto, ainda não apresentou resultados significativos, mesmo porque esta política de segurança é direcionada para a repressão e a punição da delinquência amazonense sob a ótica do Estado Penal, muito distante de se acenar para os efeitos perversos decorrentes das desigualdades sociais do Estado nacional.

\section{Referências}

ANTUNES, Ricardo. O Caracol e sua concha: ensaio sobre a morfologia do trabalho. São Paulo: Boitempo Editora, 2005.

ADORNO, Sérgio. Insegurança versus direitos humanos: entre a lei e a ordem. Tempo Social; Rev. Sociologia. USP/São Paulo, v. 11 n. 2, out. 1999, p. 129-153, (editado em fev. 2000).

Lei e ordem no segundo Governo FHC. Tempo Social; Rev. Sociol. USP. São Paulo, v. 15, n. 2, p. 103-140, nov. 2003.

BEATO FILHO, Cláudio C. Políticas públicas de segurança e a questão policial. São Paulo em Perspectiva, v. 13, n. 4, p. 13-27, 1999.

BERCOVICI, Gilberto. Constituição Econômica e desenvolvimento: uma leitura a partir da Constituição de 1988. São Paulo: Malheiros, 2005.

BRASIL.Constituição.Brasília.Disponívelem:<http://www.planalto.gov.br/c civil_03/Constituicao.htm>. Acesso em10 jul. 2014.

BRASIL. Ministério da Justiça. PRONASCI. Um novo paradigma para a segurança pública. Brasília, DF [2009 a].

- Ministério da Justiça. PRONASCI. Gabinete de Gestão Integrada Municipal - GGIM. Brasília, DF [2009 b]. 
DÉCIMO SEGUNDO (12..$^{\circ}$ CONGRESSO DAS NACÕES UNIDAS SOBRE PREVENCAAO AO CRIME E JUSTIÇA CRIMINAL. Discurso de abertura. Disponível em:<htpp://www.crimecongress2010.com.br $>$. Acesso em: 02/08/2014.

BRASIL. Presidência da República. Ministério da Justiça. Programa Nacional de Segurança Pública com Cidadania - PRONASCI. Brasília. Disponível em:<http://www.pronasci.gov.br/ notícias.htm>. Acesso em 11 ago. 2014.

CASTEL, Robert. As metamorfoses da questão social. Petrópolis: Vozes, 1995.

CUNHA, Edite da Penha; CUNHA, Eleonora Schettini M. Políticas públicas sociais. In: CARVALHO, Alysson; SALLES, Fátima; GUIMARÃES, Marília; UDE, Walter (orgs.). Politicas públicas. Belo Horizonte: UFMG, 2008.

DORNELLES, João Ricardo W. O sistema penal construindo a figura do inimigo: a criminalização dos pobres como estratégia hegemônica neoliberal. In: BITTAR, Eduardo C. B.; TOSI, Giuseppe (orgs.). Democracia e Educação em Direitos humanos numa época de insegurança. Brasília: Secretaria Especial dos Direitos Humanos da Presidência da República, 2008. pp. 335-338.

FEITOSA, Maria Luiza P. de A, Mayer. Paradigmas Inconclusos: os contratos entre autonomia privada, a regulação estatal e a globalização dos mercados. Coimbra: Coimbra Editora, 2007.

FUNDAÇÃO GETÚLIO VARGAS. PRONASCI em números. Janeiro de 2009. Disponível em: http://www.fgv.br/fgv.projetos.htm. Acesso em 12 ago. 2014.

GOVERNO DO ESTADO DO AMAZONAS. Anuário Estatístico da Segurança Pública. Manaus, 2013.

HEIDEMANN, Francisco G. Do sonho do progresso às políticas de desenvolvimento. In: HEIDEMANN, Francisco C.; SALM, José Francisco (orgs.). Politicas públicas e desenvolvimento: bases epistemológicas e modelos de análise. Brasília: UNB, 2009.

KARAM, Maria Lucia. O sistema penal brasileiro: diagnósticos e perspectivas. In: MINAS GERAIS. Governo do Estado. Secretaria de Estado de Defesa Social-Superintendência de Prevenção à Criminalidade. As penas alternativas como prevenção à criminalidade. Revista do Programa Central de Penas Alternativas do Estado de Minas Gerais. Ano 2, n. 2. Minas Gerais: SEDH, 2008, pp. 26-32.

MENY, Ives e THOENIG, Jean Claude. Las politicas públicas. Barcelona: Ariel,1995. 
PEREIRA, Potiara P. Discussões conceituais sobre política social como política pública e direito de cidadania In: BOSCHETTI, Ivanete e outras (orgs.) Política Social no capitalismo: Tendências contemporâneas. São Paulo: Editora Cortez,2008, p.87-108.

REVISTA CAPITAL. N. ${ }^{\circ}$ 205, agosto, 2014.

REVISTA EXAME DIGITAL. Depois de 1 década nivel de miséria volta a subir no Brasil. Disponível em: http://www.exame.abril.com.br. Acesso em 10 nov. 2014.

ROLIM, Marcos. A segurança como desafio aos Direitos Humanos. In: BRASIL. Presidência da República. Secretaria Especial de Direitos Humanos. Brasil Direitos Humanos, 2008: A realidade do país aos 60 anos da Declaração Universal. Brasília: SEDH, 2008, pp. 275-277.

RUEDEGER, Marco Aurélio; RICCIO, Vicente. O novo contrato social: desenvolvimento e justiça em uma sociedade complexa. In: CAVALCANTE, Bianor Scelza; RUEDIGER; SOBREIRA, Rogério (orgs.). Desenvolvimento e construção nacional: políticas públicas. Rio de Janeiro: FGV, 2005.

SANTORO, Emilio. As políticas penais na era da globalização. In: LYRA, Rubens Pinto (org.). Direitos humanos: os desafios do século XXI. Uma abordagem interdisciplinar. Brasília: Brasília jurídica, 2002, pp. 57-72.

SCHERER, Elenise F. Tempos de contrarreforma. Manaus: Valer Editora, 2001.

SOARES, Luiz Eduardo. Segurança Pública: presente e futuro. Estudos Avançados, v. 20, n. 56, p.91-106, 2006.

SOUZA, Celina. Políticas públicas: uma revisão da literatura. Sociologias, v. 8, n. 16, p. 20-45, 2006.

WACQUANT, Loïc. As prisões da miséria. Rio de Janeiro: Jorge Zahar, 2001. . Punir os pobres: a nova gestão da miséria nos Estados Unidos. Rio de Janeiro: Editora Revan, 2007.

WERNECK VIANNA, Luiz. O terceiro poder na carta de 1988 e a tradição republicana: mudança e conservação. In: OLIVEN, R. G.; RIDENTE, M.; BRANDÃO, G. M. A Constituição de 1988 na vida brasileira. São Paulo: Hucitec, 2008.

WAISELFISZ, Julio Jacobo. Mapa da Violência 2013 - Mortes Matadas por Armas de Fogo. Rio de Janeiro: CEBELA e Flacso Brasil, 2013a. 
WAISELFISZ, Julio Jacobo. Mapa da Violência 2013 - Homicídios e Juventude no Brasil. Rio de Janeiro: CEBELA e Flacso Brasil, $2013 \mathrm{~b}$.

WAISELFISZ, Julio Jacobo. Mapa da Violência 2014 - Os Jovens do Brasil. Rio de Janeiro: Flacso Brasil, 2014.

ZALUAR, Alba. Exclusão e políticas públicas: dilemas teóricos e alternativas politicas. Revista Brasileira de Ciências Sociais, vol. 12, n. 35, p. 199. 